\title{
NOTICIARIO \\ Nuevo examen de los grabados paleolíticos de El Pendo (Cantabria, España). Consideraciones sobre las aves del arte paleolítico de la Península Ibérica
}

\author{
A new study of the Palaeolithic engravings at El Pendo (Cantabria, Spain). Thoughts \\ on birds in Palaeolithic art in the Iberian Peninsula
}

\author{
Jesús Jiménez Guijarro (*) \\ Antonio Sánchez Marco (**) \\ Marcos García Díez $(* * *)$
}

\section{RESUMEN}

La presencia de aves en el repertorio iconográfico del arte rupestre paleolítico es muy escasa. Desde 1907 se vienen describiendo unas figuras de alca y de rapaz (probablemente buitre) en la parte final de la cueva de El Pendo. Los autores las asignan a un momento antiguo, desde el Auriñaciense hasta el Magdaleniense inferior. Una nueva lectura del conjunto de grabados permite apuntar la presencia inequívoca de una imagen de ave, sin características que permitan su identificación taxonómica precisa. El trabajo revisa, además, las imágenes de aves conocidas en el arte rupestre paleolítico de la Península Ibérica.

\begin{abstract}
Birds are very scarce in Palaeolithic rock art. Since 1907 figures of razorbill and raptors (probably vulture) have been described at the end of the Pendo cave, both attributed to an Upper Palaeolithic origin (from Aurignacian to Lower Magdalenian, depending on the authors). The new revision of the group of engravings shows the presence of an unambiguous bird, but the morphology of the figure did not permit its precise taxonomic
\end{abstract}

(*) Área de Prehistoria e Historia Antigua. Edificio Departamental, casillero n. ${ }^{\circ}$ 104. Universidad Rey Juan Carlos - Campus de Fuenlabrada. Camino del Molino s/n. 28943 Fuenlabrada. Madrid. Correo e.: jesus.jimenez.guijarro@urjc.es

(**) Museo Nacional de Ciencias Naturales - CSIC. C/ José Gutiérrez Abascal 2. 28006 Madrid. Correo e.: mcnas539@mncn.csic.es

(***) Dept. de Geografía, Prehistoria y Arqueología. Universidad del País Vasco. C/ Tomás y Valiente s/n. 01006 Vitoria. Correo e.: diez.garcia.marcos@gmail.com

Recibido: 6-X-2009; aceptado: 29-I-2010. identification. The work also presents a revision of the birds known in Iberian Palaeolithic rock art.

Palabras clave: Arte rupestre; Península Ibérica; Avifauna; Pleistoceno.

Key words: Rock art; Iberian Peninsula; Birds fauna; Pleistocene.

\section{INTRODUCCIÓN}

La cavidad de El Pendo (Escobedo de Camargo, Cantabria) (Fig. 1) fue descubierta por Marcelino Sanz de Sautuola en 1878, siendo objeto de diversas excavaciones por dicho investigador y Vilanova y Piera entre 1878 y 1890 . Más tarde, Alcalde del Río, Obermaier y Breuil dirigen otra campaña en 1908, Beatty, Breuil y Carballo en 1910, y Shalcrass y Orestes Cendrero en 1914. Carballo dirigió las excavaciones de mayor envergadura entre 1924 y 1934 y entre 1941 y 1945 , y Martínez Santa-Olalla entre 1953 y 1957. En estas intervenciones arqueológicas se obtuvo un importante conjunto de elementos de arte mueble. Montes y Sanguino (2001) excavaron entre 1994 y 2000 .

Alcalde del Río encontró los grabados del divertículo final de la cavidad de El Pendo en 1907 (Fig. 2). Hasta esa fecha no se conocía ninguna representación de figuras de ave en el arte rupestre paleolítico europeo. En 1909 Breuil descubrió una nueva imagen de ave en la cueva de Gargas (Hautes-Pyrénées). Tan sólo unos meses después 


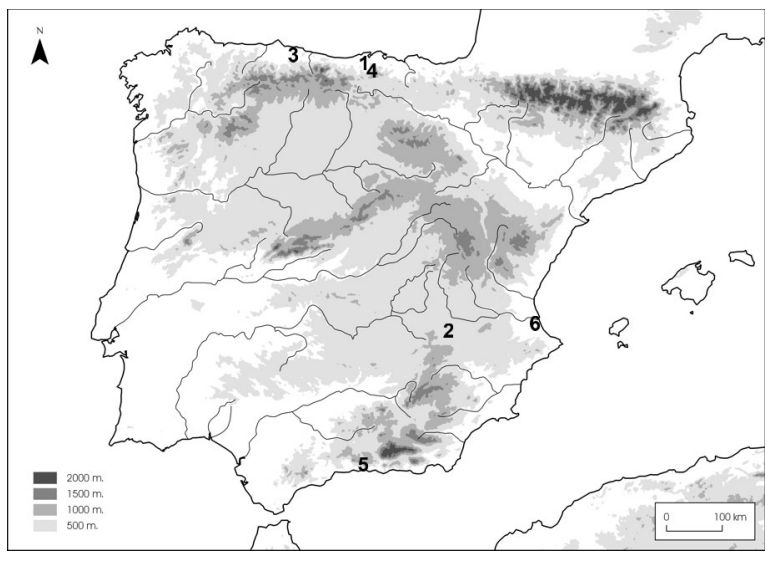

Fig. 1. Topografía y localización de la cueva de El Pendo (Escobedo de Camargo, Cantabria) y de los yacimientos peninsulares con representaciones de aves: 1. El Pendo; 2. Ambrosio; 3. El Buxu; 4. La Pasiega; 5. Nerja; 6. El Parpalló.

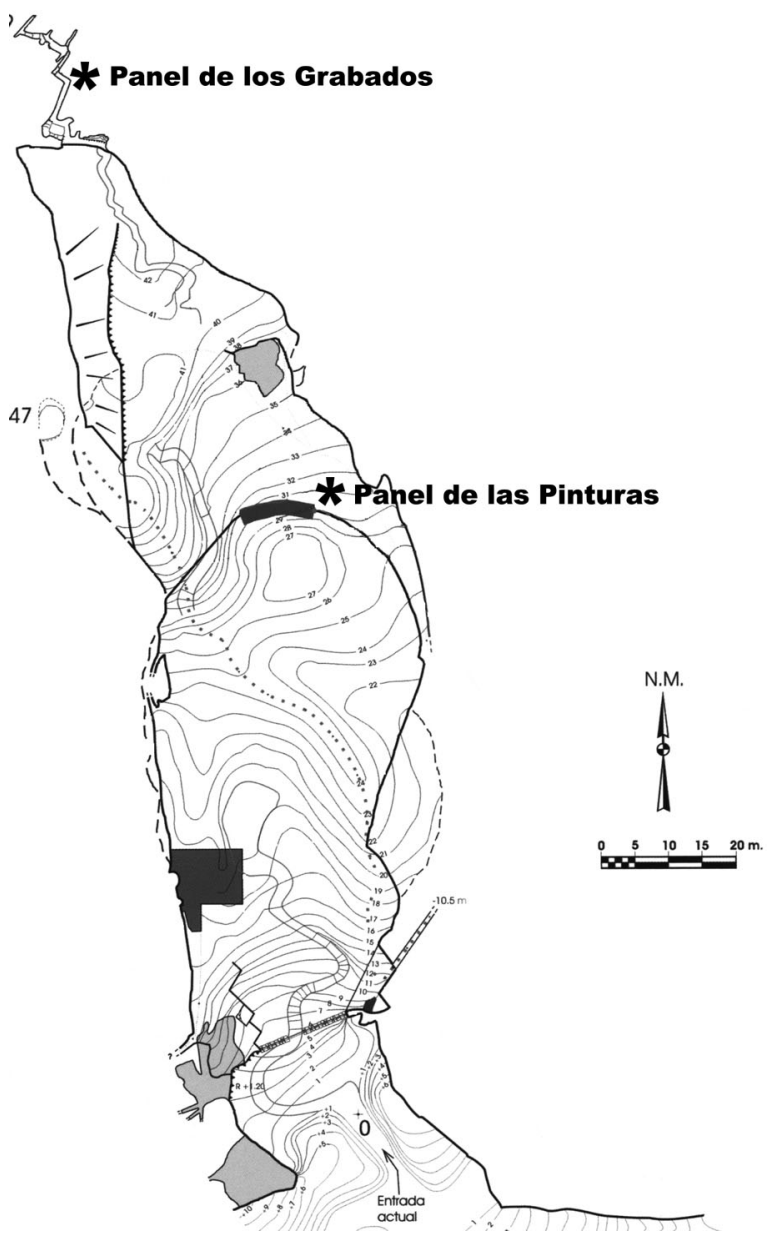

Fig. 2. Topografía de la cueva de El Pendo (Escobedo de Camargo, Cantabria) con la localización y vista del sector de grabados (a partir de Montes y Sanguino 2001). del hallazgo de El Pendo los grabados fueron objeto de calco y análisis por parte del abate Breuil, pero su publicación se aplazó hasta 1911 (Alcalde del Río et al. 1911).

La interpretación morfológica de las figuras ha sido objeto de discusión. En la publicación inicial (Alcalde del Río et al. 1911) los grabados se identificaron como un pingüino y una rapaz, probablemente un buitre. La idea del pingüino, más correctamente en nuestros días alca gigante, la retoman Reinach (1913) y Obermaier (1925). González Morales (1980) asume la interpretación de Alcalde del Río et al., mientras que Sieveking (1962) y Madariaga de la Campa (1969) dudan de su correspondencia con algún tipo de alca. Otros autores ni siquiera las señalan en sus obras (Graziosi 1956; Ucko y Rosenfeld 1967; Leroi-Gourhan 1965) o yerran al asignar las representaciones de aves a su conjunto de arte mueble (Almagro 1947; Glory 1965). Barandiarán (1980) realiza el estudio más completo y concienzudo recogido en la memoria de González Echegaray sobre el yacimiento. González Morales (1980) presenta otro artículo en esta obra y concluye que ambos grabados corresponden incuestionablemente a dos alcas gigantes.

Dada la polémica atribución de las figuras grabadas en el panel de El Pendo, se llevó a cabo su análisis, utilizando como base una nueva revisión de campo.

\section{METODOLOGÍA}

El trabajo de campo se llevó a cabo en 2002 en dos jornadas (1). Se realizó un calco y un amplio reportaje fotográfico sobre papel (color, blanco y negro e infrarrojos), con equipo Nikkon F-3 (35 mm) y Rolleyflex $(120 \mathrm{~mm})$, y sobre soporte digital, con equipo Ricoch de 3.1 MP dotado de macro $1 \mathrm{~cm}$. Para la iluminación se emplearon dos focos halógenos con potenciómetro. Los efectos de la distorsión se minimizaron obteniendo diversas tomas fotográficas planas mediante trípode y otros sistemas de estabilización de imagen. Los productos fotográficos resultantes sobre película diapositiva a color de 35 y $120 \mathrm{~mm}$ fue-

(1) Corrió a cargo de J. Jiménez y A. Sánchez. Fue autorizado por la Consejería de Cultura, Turismo y Deporte del Gobierno de Cantabria a través de la gestión realizada por el Museo Arqueológico Regional de la Comunidad de Madrid, que agradecemos a su Director, E. Baquedano. 
ron utilizados para levantar un calco usando una plataforma vertical de transparencias.

En la cavidad se analizaron las paleo-huellas -estrías, evidencias de repasados, etc.- sobre el soporte con lupas portátiles de 5 y 10 aumentos. También se prestó especial atención al estudio paleográfico del soporte siguiendo un método similar al estratigráfico: una documentación exhaustiva de todas y cada una de las superposiciones y de las relaciones existentes entre las diversas líneas observadas.

\section{FASES DE EJECUCIÓN DEL PANEL DE GRABADOS}

Barandiarán (1980) señala las notables diferencias entre sus calcos y los de Alcalde del Río et al. (1911). Además de las divergencias respecto a la realidad en la representación de las líneas grabadas, este autor las reconstruye en el orden de prelación de las imágenes del calco de Alcalde del Río et al. (Tab. 1A). Barandiarán (1980: 251) nota también diferencias en los gestos técnicos con los que fueron efectuados los grabados, advirtiendo que por la pátina y los restos de costra

\begin{tabular}{|c|c|c|}
\hline Autor/es & Figuras identificadas & $\begin{array}{l}\text { Orden de } \\
\text { prelación }\end{array}$ \\
\hline $\begin{array}{c}\text { A } \\
\text { (Alcalde del } \\
\text { Río et al.) }\end{array}$ & $\begin{array}{l}\text { Dorso cuadrúpedo } 1 \\
\text { "Buitre" o rapaz } \\
\text { Dorso cuadrúpedo } 2 \\
\text { "Pingüino" }\end{array}$ & $\begin{array}{l}1 \\
2 \\
3 \\
4\end{array}$ \\
\hline $\begin{array}{c}\text { B } \\
\text { (Barandiarán) }\end{array}$ & $\begin{array}{l}\text { Cuadrúpedo inferior } \\
\text { Ave }\end{array}$ & $\begin{array}{l}1 \\
2\end{array}$ \\
\hline $\begin{array}{c}\mathrm{C} \\
\text { (estudio actual) }\end{array}$ & $\begin{array}{l}\text { Cuadrúpedo a derecha } \\
\text { Ave a izquierda } \\
\text { Grabados finos superior } \\
\text { derecha } \\
\text { Grabados gruesos infe- } \\
\text { riores } \\
\text { Grabados históricos cen- } \\
\text { trales } \\
\text { Grabados históricos } \\
\text { Alteraciones antrópicas } \\
\text { modernas }\end{array}$ & $\begin{array}{c}1 \\
2 \\
1-2 \\
3 \\
4 \\
5 \\
6\end{array}$ \\
\hline
\end{tabular}

Tab. 1. Orden de prelación en el panel de grabados de la cueva de El Pendo (Escobedo de Camargo, Cantabria) según Alcalde del Río et al. (1911), Barandiarán (1980) y el presente estudio. de calcita parecían corresponder a dos momentos. Los trazos de aspecto más grueso serían los modernos, frente a los de surco más estrecho a los que atribuye una cronología prehistórica. Barandiarán reduce de forma notable las figuras observadas y sus seriaciones.

El nuevo estudio arroja unas conclusiones similares a las obtenidas por Barandiarán, si bien se advierten ciertas divergencias (Tab. 1B) que es preciso explicar. Actualmente el estado general del panel de los grabados es lamentable. Se encuentran en una estrecha zona de paso, objeto de numerosas alteraciones que incluyen el trazado de flechas e indicaciones de la dirección de la marcha y salida desde la gatera, que conduce desde la zona profunda de la cavidad hacia el corredor de la sala principal, tras el laminador, y desde éste hasta el acceso actual a la caverna. Estas nuevas grafías han sido realizadas sobre el soporte de los grabados prehistóricos (Fig. 3), pero afortunadamente no se les superponen.

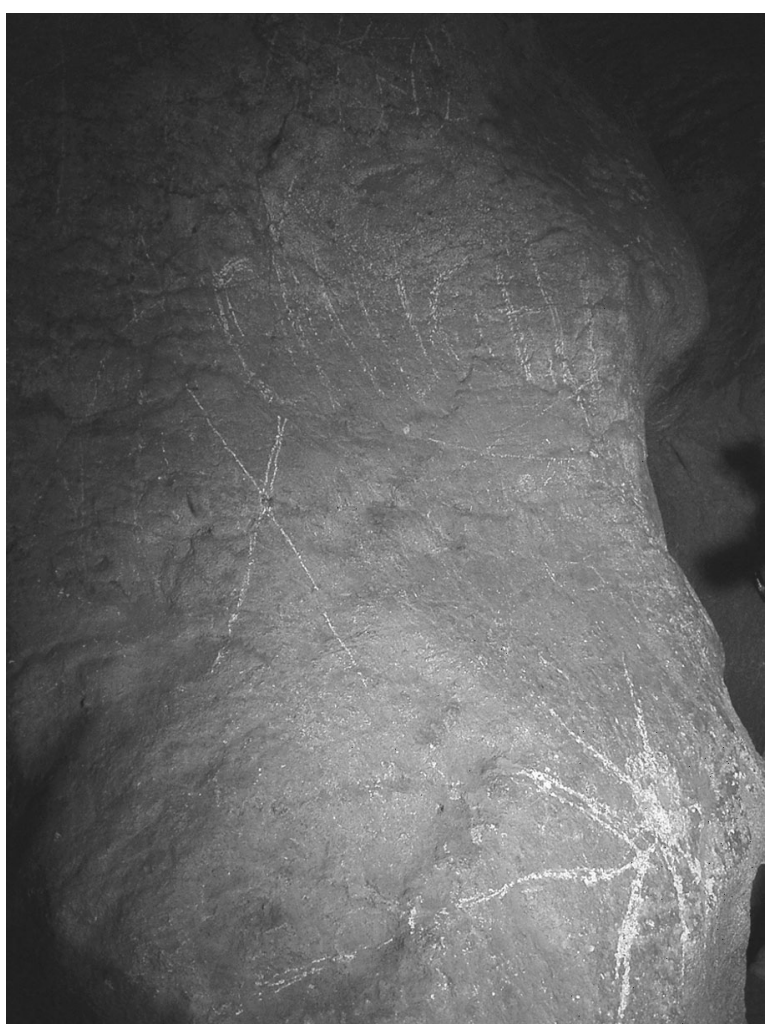

Fig. 3. Vista general del estado actual del panel de grabados de la cueva de El Pendo (Escobedo de Camargo, Cantabria). Los grabados visibles corresponden a alteraciones modernas (algunas muy recientes) realizadas sobre el panel de grabados prehistóricos. 
Atendiendo a los criterios de superposición y al análisis de los gestos técnicos empleados en la elaboración de los grabados, se han podido identificar hasta seis momentos o fases diferentes de utilización del soporte (Tab. 1C). La desconexión espacial entre los grabados más antiguos -de temática animal- y los localizados en el extremo superior derecho del panel impide señalar con certeza a qué momento pertenecería cada uno de ellos. No obstante, el gesto técnico y las paleo-huellas localizadas en el interior de estos grabados finos permiten suponerlos contemporáneos de los momentos 1 ó 2, al tiempo que los distancia de forma notable de las restantes fases.

\section{MORFOLOGÍA Y DESCRIPCIÓN DE LOS GRABADOS HISTÓRICOS}

El estudio del soporte, de la composición estratigráfica del panel y de los diferentes elementos grabados introduce nuevos elementos en la lectura del grafismo. En primer lugar se advierte un panel conformado a modo de palimpsesto en el que se superponen diferentes conjuntos de grabados (Fig. 4A) desarrollados en seis fases.
Al menos tres etapas de grabado deben ser consideradas históricas, por la presencia de grafías alfabéticas identificables (Fig. 4B). La fase 4 debe ser anterior a 1913 ya que se superpone a la fase 5, que contiene un trazado de ese año. Posteriormente se llevan a cabo sobre ambas diferentes líneas (algunas en forma de flecha) cuyo objetivo es indicar la marcha durante el tránsito por la cueva (fase 6).

De la fase 4 tan sólo se puede leer "A N", mientras que los surcos de la fase 5 son más superficiales que los de fase 2 y fueron probablemente trazados con un objeto metálico. En una maraña de líneas inconexas se advierte el siguiente texto dispuesto en tres líneas: 1913 / AGO[sto] / CHUCHI

Como se aprecia en el calco (Fig. 4) y en la fotografía (Fig. 5), en este mismo momento y, presumiblemente, con el mismo objeto, se remarcaron algunas de las líneas principales de los grabados prehistóricos, especialmente el correspondiente al ave que forma el motivo central, quizás para hacer más visibles las líneas principales de lo que alguien debía registrar en un calco o en un dibujo o quizás por un deseo de falsear la obra original. Parece apoyarlo el que se repase, preci-
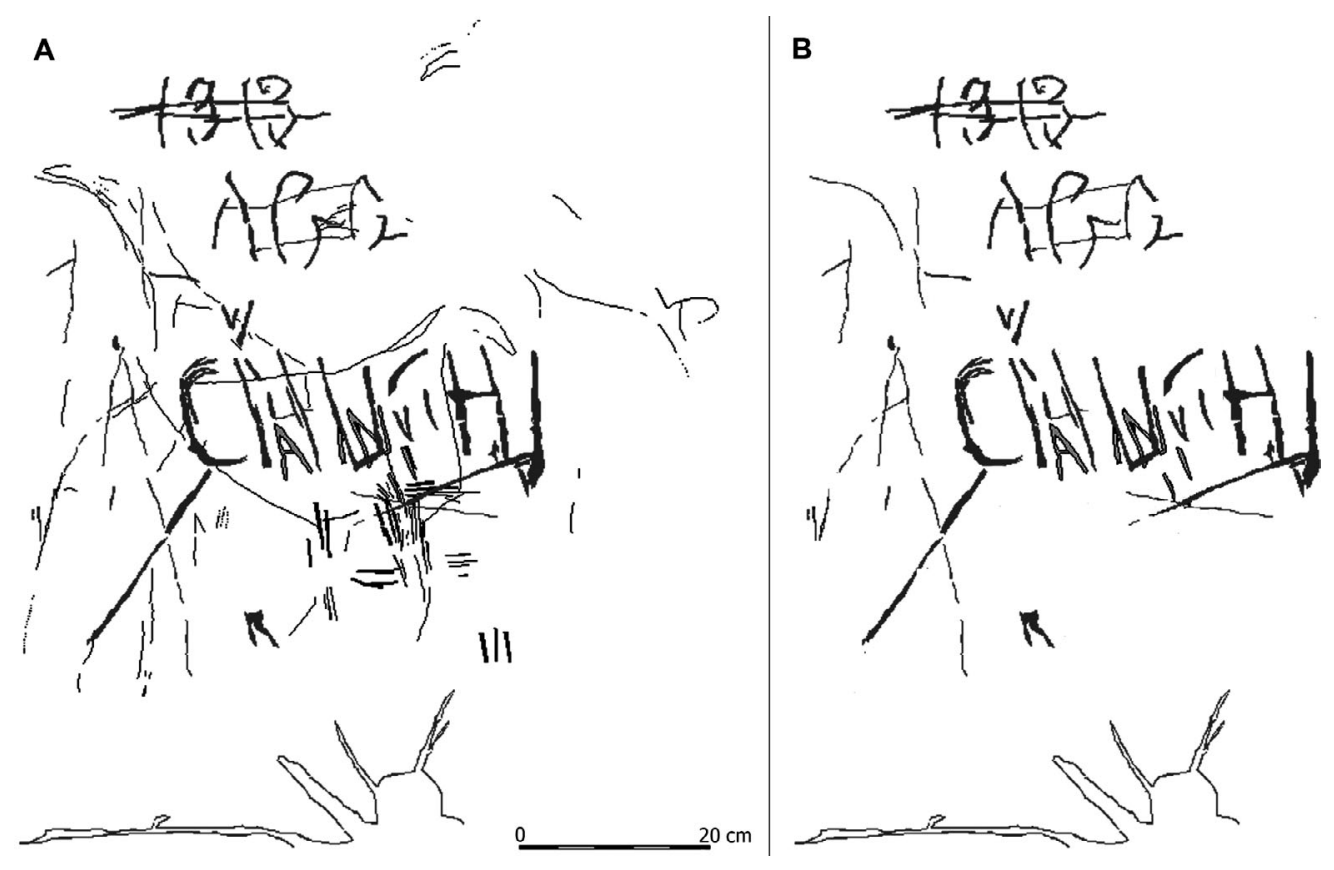

Fig. 4. Calco completo del panel de grabados de la cueva de El Pendo (Escobedo de Camargo, Cantabria): A. completo, en trama fina prehistóricos y en trama gruesa modernos; B. selección de trazos modernos y contemporáneos. 


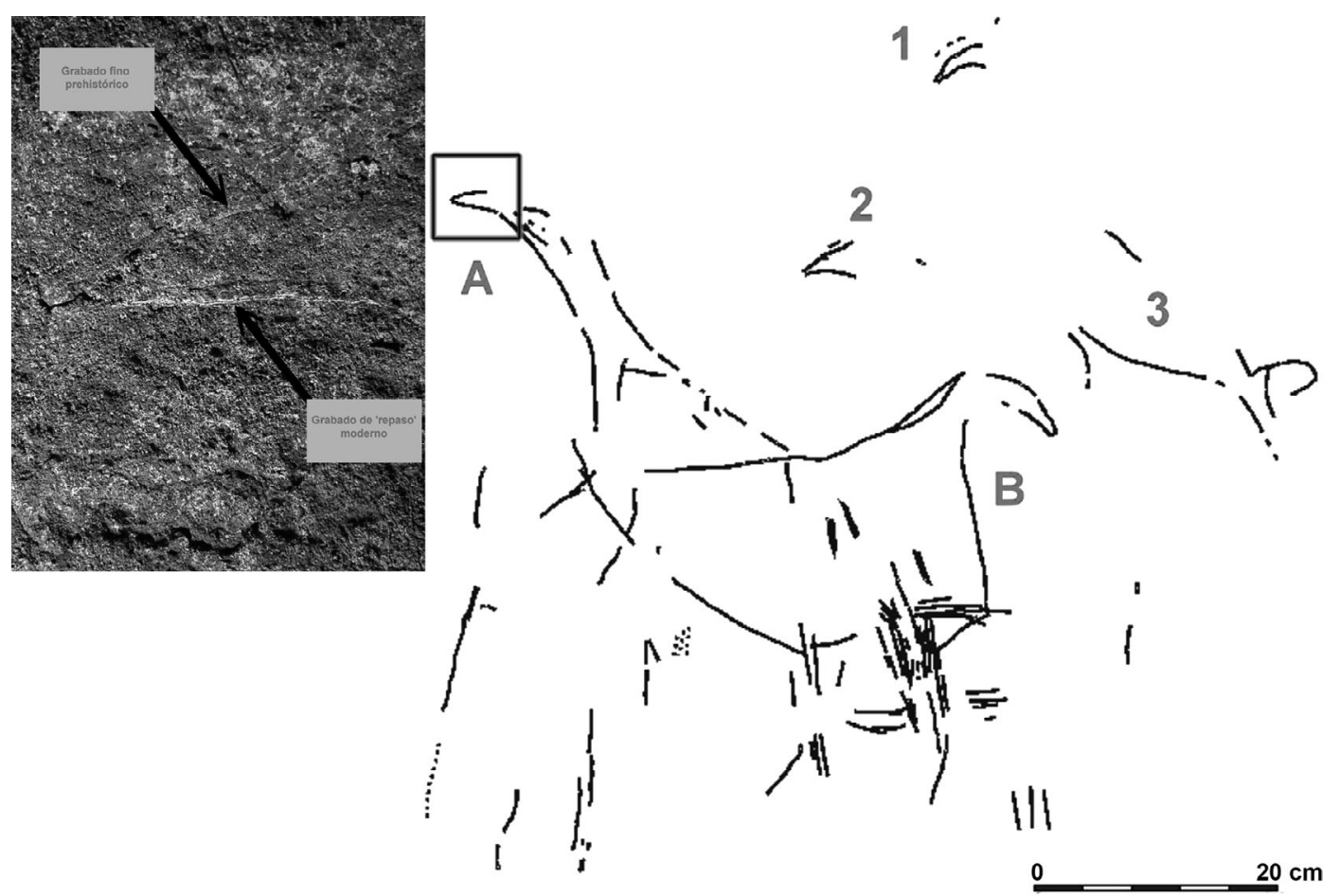

Fig. 5. Calco de grabados prehistóricos del panel de la cueva de El Pendo (Escobedo de Camargo, Cantabria): A. prótomo de ave y B. prótomo de équido. 1 a 3: posibles zoomorfos. El recuadro corresponde a la macrofotografía del extremo distal del pico del ave y del repasado posterior.

samente, la zona más clara de la curva de inflexión de la parte interna del prótomo de lo que Breuil interpretó como alca gigante. También cabe señalar un conjunto de grabados lineales, más anchos y profundos (fase 3), que dan lugar a agrupaciones o haces de líneas y que, según se ha podido documentar, se sitúan sobre los grabados finos paleolíticos y bajo los históricos. Tanto Alcalde del Río et al. (1911) como Barandiarán (1980) consideran estas líneas sincrónicas a la ejecución de los grabados finos, sin reparar ni en la diferencia del gesto técnico ni, sobre todo, en la existencia de superposiciones.

Bajo todo este conjunto, ciertamente caótico, se desarrolla una serie de grabados muy finos, ejecutados con un objeto aguzado de filo estrecho y que constituye el cuerpo principal del panel, la fase paleolítica. Aún por debajo de este conjunto de grabados antrópicos se localiza una no menos destacada serie de líneas y pseudo-grabados de origen natural, que forman parte del soporte calizo. Tanto Alcalde del Río et al. (1911) como Barandiarán (1980) los confunden, en ocasiones debido a la notable dificultad de definición, con líneas de graba- do que interpretan como parte del panel paleolítico, desvirtuando por ello el resultado final de su levantamiento y posterior interpretación.

\section{MORFOLOGÍA Y DESCRIPCIÓN DE LOS GRABADOS PALEOLÍTICOS}

El soporte pétreo original no fue objeto de preparación con antelación a la ejecución de los grabados paleolíticos. Tampoco ha sido empleado como un elemento más de integración gráfica para dar volumen o completar las figuras.

En el calco ahora presentado, y coincidiendo con Barandiarán (1980), se definen dos figuras nítidas (Figs. 5 y 6), entre las que, a falta de superposiciones, no se puede asegurar la sincronía ni la primacía temporal de una de ellas. Además, en el sector derecho del panel se observan, al menos, dos conjuntos de líneas angulares y una serie de líneas curvas que pudieran asignarse, no sin dudas, a sendos prótomos y parte de una línea cérvico-dorsal. Todas ellas corresponden a grabados parcialmente desaparecidos (Fig. 5). 


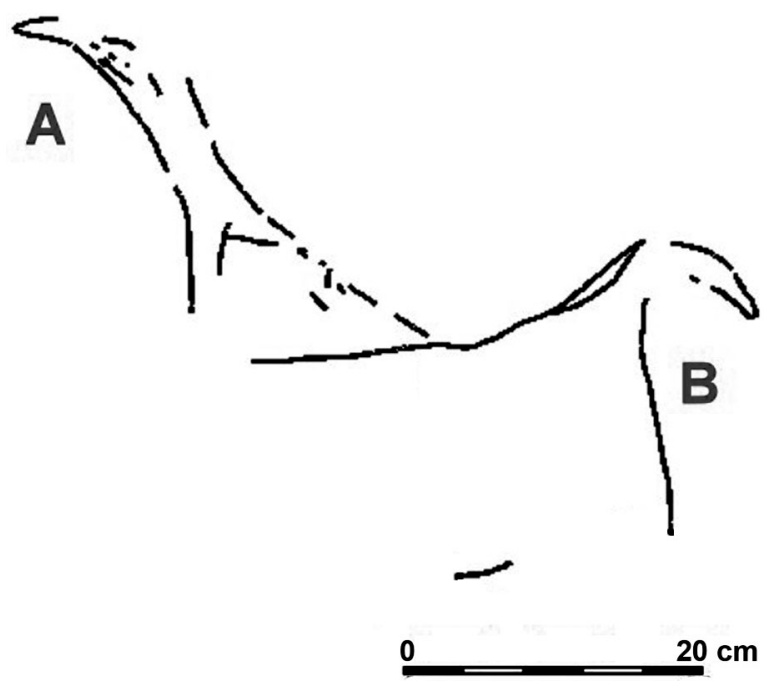

Fig. 6. Detalle del calco con la representación de los grabados paleolíticos figurativos de la cueva de El Pendo (Escobedo de Camargo, Cantabria): A. prótomo de ave y B. prótomo de équido.

Figura A (Fig. 6): es la situada a la izquierda en los calcos de Alcalde del Río et al. (1911) y Barandiarán (1980). Se trata de la supuesta alca o pingüino según Breuil y del anseriforme según Barandiarán (1980). La figura está incompleta, en contra de lo que señalan estos autores. Se observa el claro prótomo de un ave, mirando a la izquierda, sin conexión física con las líneas del pretendido cuerpo del ave. La línea que otros autores identifican como parte de su pechera es independiente de las líneas de arranque del cuello y, además, muestra un surco ligeramente más estrecho que aquél con el que se realizó el prótomo. En el interior de lo que podría ser el cuello y la cabeza del ave aparecen una serie de líneas que bien pudieran interpretarse como parte de un plumaje o de la anatomía del ave, si bien no tienen parecido alguno con el relleno interior que Breuil señala en su calco. Ello, junto a la pretendida línea de la pechera, podría constituir un añadido ciertamente artístico por parte de este investigador. Conforme al criterio de superposición, la cronología de buena parte de las líneas situadas en el extremo inferior derecho de esta figura debe ser posterior. Todos los trazos de la derecha se superponen a la línea que Breuil interpretó como parte de la base del ave y que nosotros consideramos, por la morfología del trazo, más bien parte de la representación burda de la línea ventral del équido, si bien tampoco existen datos fehacientes de continuidad de trazo con esta figura que permitan asegurarlo sin dudas.

La maraña de trazos inferiores, interpretados por anteriores autores como parte del aparato locomotor de la misma ave, tampoco presenta evidencias de relación con esa figura, ni en su morfología de trazo ni en su continuidad, por lo que no creemos acertado indicar que se tratase de las extremidades del ave.

Figura B (Fig. 6): es la situada a la derecha en los calcos de Alcalde del Río et al. (1911) y de Barandiarán (1980). No cabe duda de que nos encontramos ante un cuerpo ancho, con líneas cérvico-dorsal y parte de la pectoral marcadas, asociadas - por cercanía, que no por continuidad de líneas- a otras dos formando ángulo y convergentes que pueden interpretarse como parte del prótomo de un animal. Una línea paralela convergente, situada a la altura del extremo inicial del prótomo, cuya colocación coincide en los calcos de Breuil, Barandiarán y en el ahora presentado, podría estar indicando la crin, interpretándose la figura como un esbozo de équido. No hay claros indicios de la representación de las patas, si bien es cierto que su parte inferior es la más alterada. Consideramos que tan sólo un trazo de la línea ventral asignada por otros autores a la figura del ave podría coincidir con esta figura. A esta interpretación contribuyen la morfología del trazado y su anchura, que son del todo coincidentes con los de la línea cérvico-dorsal del prótomo del équido.

Figuras 1 y 2: poco puede decirse de ellas, excepto que repiten un esquema similar al empleado para la solución de los extremos terminales superiores de las figuras A y B. Podemos apuntar, no sin incertidumbre, que se tratase de trazos de figuras perdidas.

Figura 3: pudiera corresponder a una línea cérvico-dorsal asociada al arranque del prótomo de un animal muy estilizado. No obstante, se carece de elementos de juicio suficientes desde el punto de vista de su ejecución como para identificar inequívocamente qué animal representa.

\section{IDENTIFICACIÓN ESTILÍSTICA Y DETERMINACIÓN CRONOLÓGICA DE LAS FIGURAS PALEOLÍTICAS}

El cuadrúpedo (un équido) parece más sencillo de fechar debido a los elementos morfológicos que lo componen. La dificultad para la caracteri- 
zación morfo-tipológica del ave estriba no tanto en la complejidad de su desarrollo como en la escasa muestra de comparación que existe hasta ahora en todo el arte rupestre prehistórico europeo.

La presencia en el équido de algunos convencionalismos propios de etapas arcaicas del arte parietal permite arbitrar ciertas ideas en torno a su siempre compleja adscripción cronológica. La notoria desproporción entre la cabeza, de tamaño muy reducido y morfología oblonga, y el cuerpo, macizo, avalan una cronología propia de los momentos que en la clasificación de Leroi-Gourhan (1965) se denominan "primitivos", propios del Estilo II, correspondiente al Solutrense Antiguo/ Gravetiense (c. 25-20 ka). Deben entenderse, del mismo modo, la falta de elementos definitorios del animal o el tratamiento esquematizante del conjunto. No obstante, la crinera muy someramente indicada y el notable suavizado de la línea cérvico-dorsal pudieran señalar algunas convenciones del Estilo III, propio del Solutrense superior y del Magdaleniense inicial (c. 20-16 ka). En consecuencia, la representación de este équido $y$, tal vez la mayor parte de los grabados ubicados en la zona superior derecha del panel serían de la primera fase de uso del soporte. Éste habría tenido lugar en el Solutrense avanzado, quizás en la transición entre los Estilos II y III de Leroi-Gourhan (1965), en torno al 20.000 AP.

Podría compararse el arte de esta cavidad con el de otros yacimientos de la región franco-cantábrica, como el francés de Pair-non-Pair o los cántabros de La Viña, La Lluera, Godulfo o Chufín. Resulta interesante comprobar los paralelismos existentes, empero, con conjuntos del Ciclo Auriñaco-Gravetiense con representaciones grabadas de los Estilos I-II. Entre los paralelos cabe citar las siluetas grabadas de Figuier, Huchard, Ebbou y Deux-Ouvertures en Ardèche, y Chabot y Oulen en el departamento de Gard. Todos estos elementos se presentan bajo el aspecto de un horizonte figurativo y técnico muy homogéneo, en el que se generaliza el uso de grabados muy profundos en zonas próximas a los accesos de las cavidades y más finos en los sectores internos de las mismas, a menudo formando parte de paneles cargados de palimpsestos de grabados. Es en este momento cuando con más acierto cabría incluir, quizás, los primeros grabados de El Pendo.

La ejecución del ave parece haber sido posterior al équido, aunque en contra de lo señalado por otros investigadores (Alcalde del Río et al. 1911; Barandiarán, 1980) falta una plena superposición de las líneas de grabado que configuran el ave y el equino. Si atendiésemos a este criterio deberíamos suponer que fue posterior en el tiempo, aunque sin distar mucho de la del caballo. Consiste en unas pocas líneas que conforman la morfología de la silueta de un ave. Por ello, junto a la ausencia de detalles nítidos o de despieces intencionados, se puede indicar una cronología similar para ambas representaciones, dentro de esa antes mencionada transición entre los Estilos II y III de Leroi-Gourhan (1965).

\section{EL GRABADO DEL AVE}

Los autores (Alcalde del Río et al. 1911: 39) de la primera publicación afirman que en el panel de El Pendo hay un pingüino (en la parte izquierda del conjunto) y una rapaz, probablemente un buitre (en la parte derecha). González Morales (1980: 260-261) también cree distinguir dos figuras que identifica como alcas gigantes (Pinguinus impennis). Nosotros consideramos, como Barandiarán (1980), que la única representación es la del ave situada a la izquierda del panel. La imagen del buitre es, en parte, una invención construida mediante la concatenación de trazos correspondientes al équido mencionado, que se encuentra por debajo del ave, y se completa con algunos detalles, como las plumas de la nuca de la rapaz.

Groenen (2006) también indica importantes discrepancias entre algunos calcos de pinturas rupestres realizados por Breuil, o mandados ejecutar por el investigador francés a diversos ayudantes, y la realidad representada en el panel que deberían reflejar. Esta "libertad de expresión" artística cumple hoy un importante papel de distorsión en un amplio conjunto de abrigos y cuevas estudiados por Breuil en España.

Los trazos que inequívocamente pertenecen al grabado del ave son aquellos que delinean la silueta del pico, la parte inferior del cuello hasta el comienzo del vientre y la parte posterior del cuello, que se prolonga hasta lo que sería más de la mitad de la espalda del animal. La línea superior de la cabeza no está ejecutada (Fig. 6).

Una serie de líneas podrían haber sido ejecutados por el autor del grabado para representar todo el perfil del abdomen del ave, pero no están en conexión con la parte inferior del cuello. Sin em- 
bargo, en los calcos de Alcalde del Río et al. (1911) y de Barandiarán (1980) todo el contorno abdominal aparece como una continuación del cuello, algo que no corresponde a la realidad pero que, indudablemente, da mayor coherencia a la imagen. Por otro lado, en el área de la cabeza unos trazos pequeños también podrían formar parte del dibujo del ave; en el calco de Alcalde del Río et al. (1911) éstos son más numerosos y largos. Configuran el ojo y la región periocular de "su pingüino" y delimitan la zona ventral de la cabeza y el cuello. En el calco de Barandiarán (1980) delinean, por el contrario, el ojo del animal.

Al final del cuello hay un par de trazos en ángulo recto que tampoco están en conexión con los trazos evidentes del ave. En el calco de Alcalde del Río et al. (1911) son mucho más largos: uno llega incluso hasta la base del pico y el otro parece formar parte de los cuartos traseros de un cuadrúpedo. En el de Barandiarán (1980) sólo está el trazo horizontal -más largo que en nuestro calcoque no parece formar parte del grabado del ave. La situación y dimensiones de estos trazos son congruentes con que señalaran el vértice flexor del ala grabado.

La figura de la izquierda que Alcalde del Río et al. (1911) atribuyen al pingüino está completamente delineada. La parte superior de la cabeza - que no han encontrado ni Barandiarán (1980) ni los autores de este trabajo- aparece trazada con un perfil muy bajo, como el que poseen en general las aves buceadoras. Nuestro dibujo discrepa de los de Breuil y Barandiarán en el contorno dorsal del cuerpo, que discurre desde el final del cuello hasta unas pretendidas patas en el de Breuil o unos trazos informes en el de Barandiarán. Ahora no se ha encontrado ninguna línea que pueda ser atribuida a la espalda del ave. Las patas del ave de Breuil no son tales: son una transformación imaginativa de un grupo numeroso de trazos gruesos posteriores a los grabados del cuadrúpedo y del ave. La serie de trazos cortos y paralelos del calco de Breuil, que siguen el perfil dorsal del ave y producen en el espectador una sensación de volumen, constituye una invención más.

Barandiarán (1980) atribuye, con reservas, la figura del ave a una anseriforme. Nosotros pensamos que, aunque las dimensiones relativas del pico podrían ser compatibles con esa identificación, su forma no se parece a las que poseen los picos de los patos, porrones, tarros o gansos.
Además, el cuello de la figura es corto, aunque está estirado, como lo prueba el estrechamiento que se observa en su porción media. Todas las anseriformes tienen cuellos largos, así como las garzas, grullas, cigüeñas, espátulas, moritos, flamencos, somormujos, zampullines, colimbos, cormoranes, avutardas, sisones, alcaravanes y los buitres leonado y negro, entre las aves más frecuentes. El tamaño del pico es medio. No es tan pequeño como en las galliformes, halcones, palomas y similares. Tampoco tiene un perfil ganchudo, como más o menos acusadamente tienen las rapaces o algunas gaviotas. Es más robusto que los picos de los charadriiformes, polluelas, gallinetas -aunque menos que el del rascón-, cucos, araos y similares -excepto en los casos del frailecillo y de las alcas, con picos mucho más altos- $\mathrm{y}$ de la mayoría de las passeriformes, quizá con las únicas excepciones del cuervo y de la corneja, a la que se parece mucho. Los cuervos son muy frecuentes en los sedimentos del Pleistoceno europeo depositados en conjuntos kársticos; de hecho, Fuentes (1980) identifica restos de corneja en El Pendo. Pero los córvidos, como la mayoría de las passeriformes, poseen cuellos bastante cortos.

En conclusión, este grabado parietal se corresponde inequívocamente con la imagen de un ave, pero sin características que permitan su identificación taxonómica. No posee un conjunto de rasgos morfológicos de ninguna especie. El autor del grabado quiso representar un ave, pero no dibujó ninguna en particular. Quizá pretendía plasmar una idea general de ave.

\section{LAS REPRESENTACIONES DE AVES EN EL ARTE CUATERNARIO PENINSULAR}

Las representaciones de aves en el arte cuaternario europeo son extremadamente raras (Novel 1986, 1987; Crémadès 1993; Sanchidrián 2001). La diferencia tan evidente con que son tratadas las diversas temáticas en el arte paleolítico merece una explicación, aunque por el momento sólo se puedan ofrecer algunos elementos para la discusión.

El conocimiento humano de los grandes y medianos mamíferos siempre ha debido de ser más detallado que el de las aves. Los mamíferos han constituido un recurso alimenticio o una amenaza para los mismos humanos, para sus presas de caza o para sus rebaños en épocas históricas más 
recientes. Las aves, por el contrario, nunca han representado un peligro directo para el hombre y tampoco ha habido ninguna especie que haya competido con los grupos humanos de cazadores por las mismas presas. Las aves sólo capturan mamíferos pequeños. Por lo anterior, en las culturas paleolíticas -cuanto más en las más antiguases probable que los humanos conocieran mejor los detalles morfológicos y el comportamiento de los mamíferos que los de las aves. Así, los mamíferos formarían parte del campo de experiencias más importantes de los grupos humanos. En consecuencia, tendrían mucho más peso en el arte paleolítico -como parece evidenciar el registro arqueológico-que las aves. Ello ocurriría tanto si las representaciones rupestres tenían una función ritual o trascendente (Breuil 1934, 1952; Clottes 1996), propiciatoria para el éxito en la caza (Reinach 1913), encerraban un simbolismo sexual (Leroi-Gourhan 1965), eran reflejo de divisiones territoriales o étnicas (Moure 1994; Mellars 2006), además de expresar algún tipo de división territorial, estaban relacionadas con actividades estacionales de estas sociedades (Utrilla 1994;
Cantalejo y Espejo 1997; Ramos et al. 1999) o simplemente eran consecuencia de la admiración e interés que los animales despertaban en los grupos de cazadores.

Probablemente las aves comenzaron a incorporarse al campo de las experiencias humanas con el aumento en la complejidad de las culturas y sociedades paleolíticas y, sobre todo, con los cambios en el espectro de recursos alimentarios que se fueron produciendo con los cambios medioambientales. Quizá estas condiciones fechan la entrada de las aves en el arte rupestre. Según esta línea argumental -la de la pertenencia al campo de experiencias de los grupos humanos-, los reptiles, anfibios y pequeños mamíferos prácticamente no se representan en el arte de las cuevas.

Cualesquiera que hayan sido las funciones que han tenido las representaciones de animales para los diversos grupos humanos, en la inmensa mayoría de los casos las imágenes de los mamíferos son reconocibles y pueden ser atribuidas, más o menos fácilmente, a una u otra especie. No sucede lo mismo con las aves. Algunos grabados (Fig. 7) son imágenes bastante fieles: el posible

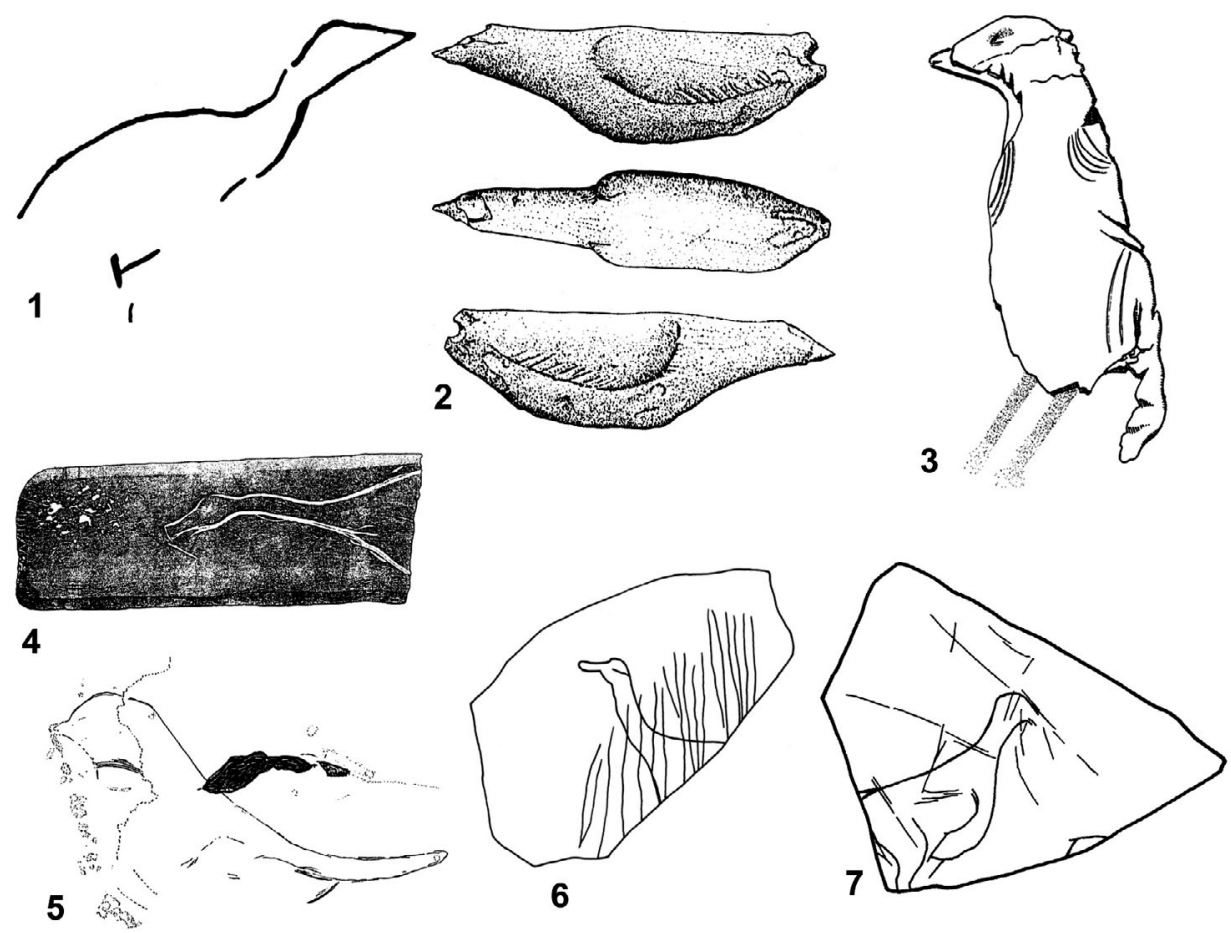

Fig. 7. Representaciones de aves en yacimientos paleolíticos ibéricos (a diferentes escalas): 1. Ambrosio (Ripoll 1994); 2. El Buxu (Menéndez 1992); 3. La Pasiega (Glory 1965); 4. Nerja (Cremades 1997); 5. La Pasiega (Castillon 1997); 6 y 7. El Parpalló (Villaverde 1994). 
flamenco de la cueva de Ardales (Málaga) (Cantalejo et al. 2003), y dos patos en plaquetas de El Parpalló (Valencia) (Villaverde 1994) y Nerja (Málaga) (Cremades et al. 1997). También en El Parpalló se encontró una placa con el grabado del cuerpo completo de una perdiz (Villaverde 1994). El flamenco de Ardales por su posición está vivo, mientras los autores de las otras figuras parecen haber tenido como modelos animales muertos. Los patos de Nerja y de El Parpalló tienen los cuellos extendidos, ligeramente curvados, como los tendrían patos muertos situados en el suelo, en vez de en línea recta con la cabeza, como cuando alzan el vuelo o están volando. La perdiz que sirvió de modelo en El Parpalló no sólo estaba muerta sino también desplumada, porque el autor trazó el contorno de la pata correspondiente a la región del fémur, la rodilla y el comienzo del tibiotarso, invisibles en un ave emplumada.

Una reciente publicación ofrece un buen ejemplo de aves representadas vivas y perfectamente identificables. Una plaqueta encontrada en Gönnersdorf (Alemania) muestra los grabados, muy bien elaborados, de dos aves completas: una gallineta y un ganso (Bosinski 2006).

En otros casos, las figuras no se pueden adscribir con seguridad a ninguna especie o grupo de especies concretas. La escultura sobre un colmillo de oso hallada en la cueva del Buxu (Asturias) (Menéndez y Olávarri 1983) sin duda representa a un ave, pero no se puede avanzar más porque falta la cabeza y, además, la morfología del soporte condiciona la forma del animal resultante.

Ripoll et al. (1994) señalan que el grabado parietal de la cueva de Ambrosio (Almería) se asemeja, por la morfología del pico, a una anátida, mientras su silueta recuerda a una perdiz. Estamos de acuerdo en que ésta no coincide con la silueta de ningún ave en particular. Su cuerpo parece estar algo erguido, como en las aves corredoras, buceadoras y en los avetoros y similares. El modo como dobla el cuello está en armonía con la postura del cuerpo y con la orientación de la cabeza y la silueta triangular, consecuencia de un pico muy ancho en sentido dorso-ventral, con el que tienen algunas anátidas. La factura es buena, con trazos simples y elegantes.

En La Pasiega (Cantabria) se aprovechó una pared cuyo relieve muestra concomitancias con la figura de un ave. Sobre este relieve hay dos zonas antropizadas: en la correspondiente a la cabeza un pequeño punto de pintura roja se interpreta como el ojo y en la parte inferior se trazaron dos líneas rojas paralelas interpretadas como las extremidades (Glory 1965). González Echegaray (1964) la identifica con un águila. En este caso el pintor o pintores tenían la intención de representar un ave, pero el soporte condicionaba el resultado impidiendo definir ninguna especie en particular.

Entre las atribuciones dudosas de aves están unos trazos grabados en otra zona de la cueva de La Pasiega considerados como figuración de una galliforme o de una ortega (columbiforme) (Castillón 1997). Seguramente, Balbín y González Sainz (1993) están en lo cierto cuando indican que esos trazos no corresponden a ningún animal.

\section{CONCLUSIONES}

En el arte paleolítico hay imágenes que figuran más o menos fielmente determinadas aves, mientras que otras no pueden atribuirse a ninguna especie o grupo de especies en particular. Las segundas plantean un interrogante. Probablemente algunas de estas obras se debieran a autores con escasa destreza técnica o con conocimientos limitados de las aves, pero también es posible que algunas imágenes sin paralelo en la avifauna ibérica sean deliberas y traten de expresar gráficamente la idea del ave.

Algunos soportes condicionan la ejecución de la obra, impidiendo que el autor se exprese libremente, por lo que sería ocioso preguntarse por su intención al elaborar esa imagen. Quedan por explicar las otras imágenes sin paralelo, algunas de las cuales están dibujadas por manos expertas de gentes que, al menos, conocían la morfología externa de algunas aves.

¿Podría acercarnos esta interpretación al concurso de una serie de ideas asociadas a comportamientos rituales dentro de los grupos paleolíticos que las representaron? Creemos que ésta podría ser una buena base interpretativa. El animal ha constituido durante miles de años una suerte de referencia simbólica a modo de tótem, elemento referencial o espíritu -protector o agresor-. La idea de representar el animal no deja de ser una primera noción de domesticación de la naturaleza. El ser humano aprende, desde un tiempo remoto, a aprehender y plasmar sine die sobre un soporte estático una realidad dinámica. Aquellos grupos primitivos manejaban de forma controlada las coordenadas espacio-temporales básicas 
del desarrollo natural. Representar una idea en su carácter íntimo, mediante una figura perfectamente identificable en su morfología general, implica un referencia sólida para validar la hipótesis de una domesticación mental, artística, de la naturaleza. El ser humano paleolítico es capaz de captar la imagen del animal vivo o muerto, dinámico o estático para abstraerla posteriormente y reflejarla, quizás de modo no inmediato, en un soporte rígido, bidimensional, situado en un recoveco oscuro, incómodo y reservado más allá del espacio cómodo de la vida, a un paso del misterio que pudieron representar los agrestes contrastes calcáreos de la cueva. ¿No debería tener un sentido definido esta suerte de viaje? Si éste se encontraba asociado a un hecho particular, de introspección personal del artista o a un elemento de configuración de un más complejo conjunto de ritos es algo que, de momento, queda tan desfigurado como las imágenes que hemos tratado.

\section{BIBLIOGRAFÍA}

Alcalde del Río, H.; Breuil, H. y Sierra, L. 1911: Les Cavernes de la Région Cantabrique (Espagne). Vve. A. Chêne. Monaco.

Almagro, M. 1997: "El Paleolítico español”. En J. M. Jover (coord.): Historia de España I. Espasa Calpe. Madrid: 337-387.

Balbín, R. de y González Sainz, C. 1993: "Nuevas investigaciones en la cueva de La Pasiega (Puente Viesgo, Cantabria)". Boletín del Seminario de Estudios de Arte y Arqueología 59: 9-38.

Barandiarán, I. 1980: "Los grabados parietales". En J. González Echegaray (ed.): El yacimiento de la cueva de El Pendo. Bibliotheca Praehistorica Hispana 17, Instituto Español de Prehistoria, CSIC. Madrid: 249-256.

Bosinski, G. 2006: "Le grand chasseur. Réflexion sur une scène gravée de Gönnersdorf (Rhénanie, Allemagne)". En J. M. Maíllo y E. Baquedano (eds.): Miscelánea en Homenaje a Victoria Cabrera. Zona Arqueológica 7 (II): 12-22.

Breuil, H. 1934: 'L'évolution de l'art pariétal dans les cavernes et abris ornés de France". Congrès Préhistorique de France (Périgueux, 1934): 102-118. Paris.

Breuil, H. 1952: Quatre cents siècles d'art pariétal. Les cavernes ornées de l'Age du Renne. Centre d'Études et Documentation Préhistoriques. Montignac-Dordogne.

Cantalejo, P. y Espejo, M. M. 1997: “Arte rupestre del sur peninsular: consideraciones sobre los ciclos artísticos de los grandes santuarios y sus territorios de influencia”. Revista Atlántica-Mediterránea de Prehistoria y Arqueología Social 1: 77-96.

Cantalejo, P.; Maura, R.; Espejo, M. M.; Ramos, J.; Medianero, J.; Aranda, A.; Mora, J.; Becerra, M. y Castañeda, V. 2003: "Sobre los temas, las técnicas de ejecución y representación del arte paleolítico conservado en la cueva de Ardales (Málaga): avance". Pliocénica 3: 54-61.

Castillón, R. 1997: "L’autre oiseau à la Pasiega. Nouvelle lecture". Bulletin de la Société Préhistorique de l'Ariège 52: 157-164.

Clottes, J. 1996: "L'art rupestre: pourquoi?". En J. Brunet y J. Vouvé (eds.): La conservation des grottes ornées. CNRS. Paris: 23-29.

Crémadès, M. 1993: "Les oiseaux". L'art pariétal paléolithique. Techniques et methods d'étude. Comité des Travaux Historiques et Scientifiques. Paris: 173-180.

Crémadès, M.; Pellicer, M. y Sanchidrián, J. L. 1997: "Nouvelles figurations d'oiseaux de l'art mobilier paléolithique franco-espagnol". Paleo 9: 371-387.

Fuentes, C. 1980: "Estudio de la fauna de El Pendo". En J. González Echegaray (ed.): El yacimiento de la cueva de El Pendo. Bibliotheca Praehistorica Hispana 17, Instituto Español de Prehistoria, CSIC. Madrid: 217-237.

Glory, A. 1965: "L'oiseau de la Pasiega (Espagne)". Congrès Préhistorique de France (Monaco, 1959): 596-607. Paris.

González Echegaray, J. 1964: "Nuevos grabados y pinturas en las cuevas del monte del Castillo". Zephyrvs 15: 27-35.

González Morales, J. A. 1980: "Interpretación ornitológica de los grabados". En J. González Echegaray (ed.): El yacimiento de la cueva de El Pendo. Bibliotheca Praehistorica Hispana 17, Instituto Español de Prehistoria, CSIC. Madrid: 259-261.

Graziosi, P. 1965. L'arte dell'antica età della pietra. Sansoni. Florencia.

Groenen, M. 2006: "Principios de lectura del arte parietal en las cuevas decoradas del Castillo". En J. M. Maíllo y E. Baquedano (eds.): Miscelánea en Homenaje a Victoria Cabrera. Zona Arqueológica 7 (II): 42-53.

Leroi-Gourhan, A. 1965: Préhistoire de l'art occidental. Mazenod. París.

Madariaga de la Campa, B. 1969: Las pinturas rupestres de animales en la región franco-cantábrica. Institución Cultural de Cantabria. Santander.

Mellars, P. 2006: "The ecological basis of Upper Palaeolithic cave art”. En J. M. Maíllo y E. Baquedano (eds.): Miscelánea en Homenaje a Victoria Cabrera. Zona Arqueológica 7 (II): 2-11.

Menéndez, M. y Olávarri, E. 1983: "Excavaciones en la cueva del Buxu (Cardes, Cangas de Onís)". Excavaciones Arqueológicas en Asturias 1987/1990. 
Consejería de Educación del Principado Asturias. Oviedo: 69-74.

Montes, R. y Sanguino, J. (eds.) 2001: La Cueva de El Pendo. Actuaciones Arqueológicas 1994-2000. Ayuntamiento de Camargo. Santander.

Moure, A. 1994: "Arte paleolítico y geografías sociales. Asentamiento, movilidad y agregación en el final del Paleolítico Cantábrico". Complutum 5: 313330.

Novel, P. 1986: "Les animaux rares dans l'art parietal aquitain". Bulletin de la Société Préhistorique Ariège-Pyrénées XLI: 63-93.

Novel, P. 1987: "Les animaux rares dans l'art parietal aquitain". Bulletin de la Société Préhistorique Ariège-Pyrénées XLII: 83-118.

Obermaier, H. 1925: El Hombre Fósil. Memoria 9, Comisión de Investigaciones Paleontológicas y Prehistóricas. Madrid.

Ramos, J.; Cantalejo, P. y Espejo, M. 1999: “Arte de los cazadores recolectores como forma de expresión de los modos de vida. Historiografía reciente y crítica a las posiciones eclécticas de la posmodernidad". Revista Atlántica-Mediterránea de Prehistoria y Arqueología Social 2: 151-177.
Reinach, S. 1913: Répertoire de l'art quaternaire. Leroux. París.

Ripoll, S.; Muñoz, F. J.; Pérez, S.; Muñiz, M.; Calleja, F.; Martos, J. A.; López, R. y Amaya, C. 1994: "Arte rupestre paleolítico en el yacimiento solutrense de la cueva de Ambrosio (Vélez Blanco, Almería)". Trabajos de Prehistoria 51(2): 21-39.

Sanchidrián, J. L. 2001: Manual de Arte Prehistórico. Ariel. Barcelona.

Sieveking, A. y Sieveking, G. de G. 1962. The Caves of France and Northern Spain: a guide. Vista Books. Londres.

Ucko, P. J. y Rosenfeld, A. 1967: Arte paleolítico. Guadarrama. Madrid.

Utrilla, P. 1994: "Campamentos-base, cazaderos y santuarios. Algunos ejemplos del paleolítico peninsular". En J. A. Lasheras (ed.): Homenaje al Dr. Joaquín González Echegaray. Museo Nacional y Centro de Investigación de Altamira, Monografías 17, Ministerio de Cultura. Madrid: 97-113.

Villaverde, V. 1994: Arte paleolítico de la Cova del Parpalló. Estudio de la colección de plaquetas y cantos con grabados y pinturas. Diputación de Valencia. Valencia. 